\title{
LUXIÉRNAGA
}

Eduardo Moreno Contreras 


\section{Sufrimiento y sociedad contemporánea bajo consideraciones schopenhauerianas}

\section{Introducción}

En este trabajo lo que se buscará es hacer ver en qué consiste el sufrimiento en Schopenhauer, así como sus repercusiones en la comprensión del dolor en el mundo contemporáneo. Para esto lo primero que veremos está ligado tanto a la representación como a la voluntad en Schopenhauer, siguiendo con una explicación, un poco más detallada, del sufrimiento que causa la voluntad en el hombre, concluyendo con unas cuantas preguntas que surgen de este pensamiento, a las que intentaremos dar respuesta.

\section{La representación}

Siguiendo las huellas de la filosofía Kantiana, que nos enseñan lo qué es el noúmeno el fenómeno, Schopenhauer concuerda con que lo que el ser humano conoce, no es el objeto en sí, el noúmeno; sino más bien, conoce la representación del objeto que él se ha hecho, el fenómeno. Esto quiere decir que el hombre "no conoce ni un sol ni una tierra, y sí únicamente un ojo que ve el sol y una mano que siente el contacto con la tierra." "Es entonces que comprendemos que el objeto no existiría sin sujeto, pues para que exista el objeto debe forzosamente que haber un sujeto que se represente al objeto en su conciencia. El fenómeno, es decir, lo que no es, es lo que puede conocer el hombre. Y es así como se nos oculta la verdadera realidad de las cosas.

\footnotetext{
${ }^{1}$ Schopenhauer, A. (2017). El mundo como voluntad y representación, Editorial Purrúa. México. Traducción de Eduardo Ovejero Mauri, p. 21.
} 


\section{La Voluntad}

Lo único que puede conocer el hombre es el fenómeno o la cosa en sí. Pero el hombre no sólo es sujeto cognoscente, sino que también es voluntad. Primeramente, el sujeto no se conoce a sí mismo como cognoscente. El sujeto llega a su propio conocimiento porque se siente, y este sentir no es otra cosa que la mismísima voluntad, que se encuentra en todos los seres y fenómenos de la naturaleza. Esta voluntad es el objeto en sí del mundo verdadero, es el mundo visto por el que ha desgarrado el velo de Maya (un velo que no nos permite ver el mundo como en realidad es) y logra apreciar las cosas como en verdad son. La voluntad es irracional, insaciable, ciega, libre, sin finalidad; representa el anhelo de vivir y el instinto de conservación. La voluntad es la esencia del mundo.

\section{El sufrimiento que trae consigo la voluntad}

Se dijo que todo ser es fenómeno de la voluntad, y esta voluntad lo que hace es querer. Así es como vemos que todos los seres vivos, al ser fenómenos de la voluntad, lo que hacen es llevar sus vidas de deseo, en deseo, y llagan o se estacionan en el querer. El querer se manifiesta cuando se encuentra una necesidad o una falta de algo. El camino lleno de obstáculos que se recorre desde que se quiere algo, hasta que se consigue, se llama dolor, y el conseguir lo que se quiere, se le conoce como bienestar. Es entonces que vemos que el ser humano, $y$ todos los seres vivos en general, tienen necesidades $y$ faltas por montones. El dolor que trae consigo la vida es infinito, porque siempre que alcancemos a realizar un deseo de este saldrán muchos otros, lo que nos lleva a tener más dolor por alcanzar.

\section{Del sufrimiento al tedio y el hastió}

Nosotros quisiéramos pensar que todo dolor cesará cuando se satisfagan las necesidades, ya sea por una buena economía o por cualquier otra causa, pero el 
sufrimiento en la vida no es solamente el infinito cúmulo de necesidades que quieren llegar al bienestar, sino que ahí, donde cesan los deseos, es el lugar en el que nace un mal, no mejor sino igual de insoportable que el dolor del querer. Este mal se caracteriza por asechar al hombre en los momentos libres, en los que nada le afecta y tiene, aparentemente, todo controlado; es ahí, en ese preciso lugar, donde se abalanza encima de él el hastió, el tedio, también conocido como aburrimiento. Esta es la consecuencia del no querer: un sufrimiento por el cual no nos podemos quedar quietos y sentimos una gran desesperación al no tener nada que hacer. Todos hemos sido alguna vez víctimas del tedio. Para dar un ejemplo de esto, Schopenhauer menciona una obra de Lucrecio que dice lo siguiente:

Muchas veces [Oscar] sale del palacio porque está aburrido de estar en casa, y al momento vuelve, ya que no se siente mejor en la calle. Corre a caballo precipitadamente a la villa, como si llevara ayuda a una casa incendiada / al punto se cansa, apenas ha pisado el umbral se vuelve indolente, o bien, apresurado, vuelve a la ciudad y la recorre de nuevo. ${ }^{2}$

Ejemplos de tedio hay en abundancia, cada uno de nosotros podría recordar decenas de ellos. Lo importante aquí es ver cómo el hombre nunca tiene un momento de tranquilidad, ya que lo amenazan por todos los frentes.

\section{La imposibilidad de la felicidad}

Entonces, tenemos que el hombre es la objetivación o el fenómeno de la cosa en sí, es la voluntad. Esta voluntad, que es él mismo, hace que quiera. El querer lo lleva a un estado de dolor y sufrimiento, porque el querer es la manifestación de la necesidad; y cuando por fin logra calmar su necesidad, es entonces cuando se ve aquejado por el tedio. Cuando el hombre se encuentra en un estado de necesidad indudablemente sufre, y cuando no es necesitado de igual manera, sufre. Viendo esto es como nos convencemos de que una vida completamente feliz, es imposible; y, lo más que

\footnotetext{
${ }^{2}$ idem, p. 42
} 
podemos esperar de ella es que no tengamos muchas dificultades y que se nos trate lo menos grotesco posible. Ya que en esta existencia no hay tregua, "pues entre dolor y aburrimiento se pasa la vida." ${ }^{3}$ Cualquiera que haya vivido por lo menos una cuarta parte de su vida y que sus facultades mentales estén en buen estado, estará convencido de lo que aquí Schopenhauer nos dice.

\section{La afirmación de la voluntad de vivir}

Puesto que la voluntad yace en todos nosotros y somos fenómenos de ella, la voluntad se verá afirmada cuando se quiera, sin ningún tipo de control. La afirmación de la voluntad de vivir consiste en darle un sí al cuerpo, un sí a cualquier tipo de placer, un sí al sufrimiento y un sí a todo querer. El peldaño más alto que puede conseguir la afirmación de la voluntad de vivir es la reproducción. Porque, como voluntad, solamente hay una y, esta misma, se encuentra en cada ser que la conforma, entonces el deseo de que la voluntad siga su curso por medio de la reproducción es el mayor sí a la voluntad que se puede decir. Todo eso se da gracias a que no tiene el conocimiento de las ilusiones del mundo y se encuentra bajo el velo de Maya.

\section{El sufrimiento Universal}

Cuando el individuo, gracias al conocimiento, logra quitarse de los ojos el velo de Maya y puede observar que todo en el universo no es más que la misma cosa, o sea la voluntad, se desprende de su individualidad y entiende que todos los fenómenos de la voluntad no son una cosa distinta a él. Ahora ya no solamente le preocupan y contempla sus dolores como el egoísmo, sino que siente cada uno de los sufrimientos de cualquier forma de vida, entiende sus pesares, ninguno de ellos le será ajeno y obtendrá la suprema piedad al ver que no es algo diferente a los demás. Es así como el individuo siente dolor y sufrimiento por todo lo que existe, por todo el universo; siente el sufrimiento universal. Ya nunca se sentirá feliz en sus tiempos calmados con

\footnotetext{
${ }^{3}$ Ídem, p. 318.
} 
poco pesar, sino que ya no tendrá descanso del sufrimiento, pues hay otra parte de la voluntad sufriendo en este mismo momento. ¿cómo se puede afirmar la voluntad de vivir en esta situación? No se hace. Es ahí donde se empezará a negar la voluntad.

\section{La negación de la voluntad de vivir}

Teniendo conocimiento de que no existen partes, ni individuos, sino que todo es la misma esencia, no queda más remedio que negar la voluntad de vivir. La negación de la voluntad no consiste en el suicidio, porque eso es una afirmación de la voluntad disfrazada de negación, más bien, es el rechazo de los goces que traen consigo el sufrimiento y eso es lo que debemos hacer. Utilizar la voluntad para deshacernos de ella, es lo que se necesita para negarla.

\section{Las vías de la aniquilación de la voluntad}

Para Schopenhauer existen dos vías por las cuales se puede negar la voluntad: el goce estético y el ascetismo. La primera se da porque el arte atrapa totalmente al individuo y lo aleja de sus sufrimientos convirtiéndolo en nada más que un ojo contemplador. Pero el goce estético sólo funciona momentáneamente y, tarde o temprano, tendrá que salir de ahí el individuo. El otro camino que se puede seguir es el del ascetismo. El asceta es aquel que desgarró el velo de Maya y puede reconocer a la voluntad, como el artífice de todo sufrimiento y dolor. Teniendo el conocimiento de lo anterior, decide renunciar a todo goce y placer, con la misma herramienta que causa el sufrimiento: la voluntad; pero el usará el querer para destruir al querer mismo.

\section{La religión}

Schopenhauer nos dice que el hombre, para liberarse del tedio, crea dioses, santos, demonios y quien sabe cuántas cosas más, todas, basadas en sí mismo, para que, cuando ya haya eliminado completamente la necesidad de su existencia, el hastío de la 
vida no lo alcance. Los hombres combaten al hastío dejándoles ofrendas, sacrificios, y un sinfín de cosas que solamente una mente muy supersticiosa podría soportar. Lo malo de estas prácticas es que con el tiempo se van acostumbrando tanto a ellas que, cuando tienen problemas por el lado de satisfacer sus necesidades básicas, terminan procurando más la parte ficticia que se ocupaba para librar el tedio, en vez de procurar satisfacer sus necesidades. Veo una gran proximidad de este pensamiento con la realidad mexicana, pues podemos ver cómo, aunque las personas se encuentran en una posición socioeconómica muy lamentable, siguen teniendo más en cuenta sus supersticiones que el eliminar las necesidades que los aquejan.

\section{La TV y cosas modernas}

En nuestra época, así como en todos los tiempos de la humanidad, podemos encontrar diversas y muy creativas formas de luchar contra el tedio. Schopenhauer nos muestra cómo las creencias supersticiosas nos alivian de este aburrimiento que nos da la vida. En el siglo XX y XXI podemos encontrar que, gracias a los avances tecnológicos, se inventó y se sigue inventando, una cantidad enorme de diferentes aparatos que curan el tedio efectivamente. Por decir algunos ejemplos, podemos mencionar la radio, la televisión, el cine y los videojuegos. Pero no contentos con tener estos artefactos, que de vez en cuando nos quiten el aburrimiento, el genio humano continuó mejorando sus inventos hasta llegar al punto de lograr instalar un pequeño radio en el tablero de su auto, para no sentir el hastío en el tráfico; y después fabricó televisiones tan pequeñas que se pueden llevar a cualquier lado, para nunca tener que sentir ni siquiera el roce del tedio.

Todos sabemos que la imaginación y la creatividad del hombre no tienen límites aparentes, y es por esto mismo que, aunque pasen siglos, nos siguen sorprendiendo los inventos que produce. ¿Cómo va a ser posible que él no utilice todo lo que tiene al alcance de su mano para intentar aliviar uno de los dos más grandes males que le hacen sufrir? Es entonces cuando crea su obra más perfecta, innovadora, y 
contundente a la hora de luchar contra el tedio: los teléfonos inteligentes, o smartphones. En estos pequeños y delicados rectángulos hechos de metal, vidrio y coltán, yace la fusión de todos los inventos contra el hastío del siglo pasado: la radio, el cine, los videojuegos y la televisión; pero todo eso mejorado en forma de aplicaciones. Para lo que en antaño tenías que ir a una sala especial, a una consola, o por lo menos a un dispositivo diferente, ahora ya ni te tienes que mover, todo lo tienes al alcance de la mano. Pero al igual que la religión, los smartphones pronto se apoderar de nuestras vidas, y empiezan a importarnos más que las verdaderas necesidades.

¿por qué el hombre, sabiendo que este es un mundo que por sí mismo ya es insufrible, le provoca sufrimientos a los demás? Lo primero que se nos viene a la mente cuando queremos hallar la repuesta del por qué el hombre hace sufrir a los demás, es la mala educación. Muchas veces vemos como las grandes mentes de cada época se posicionan en el pacifismo, como en el caso de Einstein y Freud, y eso nos hace pensar que lo que se consigue con dotar de una buena educación al hombre es que desarrolle una gran calidad ética. Con esta calidad ética, el hombre bien educado ve el mal que hace provocándole sufrimientos al otro, y, con esa conciencia sobre el sufrimiento ajeno, intenta no volver a producir dolor en ninguna clase de ser vivo.

\section{El egoísmo de la voluntad}

La realidad nos muestra algo muy distinto. Lo que nos enseña es que el hombre, aún con buena educación y conocimiento del sufrimiento ajeno, parece que tiende a provocarlo sin temor, ni remordimiento alguno y, además, obtiene placer. Para Schopenhauer esto se debe a que la voluntad, además de ser ciega e irracional, también es antagónica a sí misma. Como la voluntad se encuentra en su totalidad, en cada individuo, ya que no está dividida en muchas partes, y, todo lo que existe, incluyendo a los seres vivos, es producto de su representación, entonces, la voluntad del individuo cree que sólo existe ella, por lo tanto, puede hacer y deshacer todo lo que quiera sin 
preocuparle los demás, aunque sea ella misma. Es por eso que el ser humano es hostil con otro ser humano y no le importa si le causa algún dolor o sufrimiento, porque no logra ver más allá de su propia voluntad o deseo.

\section{Las pulsiones freudianas}

Una teoría muy similar a la de Schopenhauer es la de las pulsiones de Freudianas. Para contestar a la pregunta anterior, Freud nos dice que en el sujeto existen dos pulsiones: una de vida, Eros, y una de muerte, Tanatos. Estas pulsiones entran en acción cuando se quiere obtener algún placer, ya sea material o abstracto. La pulsión de Eros se manifiesta cuando se coopera con el otro, cuando se usa la creatividad y, como su nombre lo dice, actuamos amando. Por su parte, Tanatos es la respuesta a nuestra pregunta, pues es la pulsión que actúa cuando el hombre hace la guerra, la destrucción $y$, en general, crea el odio. Y decimos que es muy similar ya que podemos ver que tanto Schopenhauer como Freud llegaron a percibir en la naturaleza del hombre una fuerza opuesta o antagónica a sí mismos, que también destruye al otro.

¿Por qué sigue habiendo vida si este mundo es un valle de lágrimas? Creemos que una de las mayores causas por las cuales la gente sigue existiendo y no, simple y llanamente, se suicida: es el miedo a la muerte. En un primer momento, en el que, o somos muy jóvenes o no reflexionamos las cosas, la muerte pudiera parecernos el peor destino con el que correríamos; es algo completamente normal, pues, el miedo se funda en la ignorancia, y de ignorancia tenemos mucho en nuestros primeros años. Pero después de que pasa el tiempo y podemos apreciar que no hay nada de malo en la muerte, ¿por qué no suicidarnos? Schopenhauer nos dirá que el suicidio no es la respuesta y lo hacen sólo los que aman la vida, pero no están dispuestos a aceptar sus sufrimientos. Sí en verdad quisiéramos negar la vida y sus sufrimientos, tendríamos que negar los placeres y doblegar nuestra voluntad a negarse.

Por otro lado, creemos que la cultura tiene algo que ver en este extraño fenómeno. En la contemporánea sociedad capitalista, lo que se busca conseguir es 
excitar al máximo el deseo de las personas por productos que la mayoría de las veces no necesitan para obtener una ganancia económica. Es así que, para lograr su objetivo, las empresas gastan muchísimo dinero en propaganda. Propaganda que podemos ver en todos lados. No dudaría al decir que tal vez, en un futuro, hasta veamos anuncios en los sueños. Esto provoca que el deseo irracional de las personas se vea como Londres durante la segunda guerra mundial: bombardeado todos los días por un sinfín de anuncios. El individuo se ve solo e indefenso ante una cultura que sólo lo exprime, cual naranja para un jugo. El sujeto ya no tiene tiempo, ni para pensar en lo que está haciendo, ni el por qué lo está haciendo, ahogándose en un mar de deseos que anhela satisfacer; pero, al igual que el agua salada, mientras más bebes, más sed tendrás. A este punto ya no vemos diferencia entre un ser humano y ese ratón de laboratorio presionando, desesperadamente, un botón que, mandando una pequeña descarga eléctrica a su cerebro, le da placer infinito. La cultura moderna torna a la vida en un goce, un goce que trae consigo un sufrimiento insoportable.

¿Qué es la sociedad contemporánea bajo las consideraciones schopenhauerianas del sufrimiento? Teniendo en cuenta todo lo anterior, creemos podemos decir el por qué la sociedad actual está condenada al sufrimiento, además, de cómo el tedio masivo no consume productos, sino personas. Como ya se explicó en una pregunta anterior, la cultura contemporánea, capitalista, tiene a todos los individuos sumidos en un deseo del que no pueden huir. A este punto parecería que la sociedad capitalista va encaminada a un beneficio de unos cuantos, pero esto no es así. A los que señalaríamos como los beneficiados de tan cruel artimaña sería a los empresarios dueños de las grandes empresas del mundo, ya que es a ellos a quienes llegan las ganancias de la desdicha que provocan. Pero rápidamente nos percatamos de que ese no es el caso, pues también, al igual que todos, están atrapados en la misma telaraña del deseo. Su deseo se manifiesta de diferente manera a la de los consumidores habituales: ellos también quieren conseguir un producto, pero ese producto son las personas a las que les vendará sus mercancías. Y al ser egoístas, al igual que toda la 
sociedad, no les importa el bienestar del otro. Así es cómo vemos que, al quererse adueñar su voluntad de todo lo que puede, se venden productos que de antemano ya se sabe que son dañinos para la salud. Entonces no queda ningún individuo que se salve de la voluntad egoísta de esta sociedad, todos viven por sus deseos y para sus deseos, tanto empresarios como consumidores se encuentran sin escapatoria al sufrimiento inminente de su actuar. Una sociedad del deseo como esta no podrá hallar otro destino distinto al sufrimiento y tarde o temprano morirá en las manos del aburrimiento, pues nada de lo que hace le satisface.

\section{El tedio masivo}

Ya hablamos del más grande artefacto que ha creado el hombre en su lucha infinita contra el tedio. Ahora bien, en una sociedad donde lo único que le ocupa es el querer y el consumo, tendrá un gran tedio, pues cuando no esté laborando o consumiendo no tendrá ninguna actividad que le ocupe. En ese tedio entra en juego los smartphones. Estos son un elemento imprescindible para que el sistema no se caiga a pedazos por el aburrimiento. A lo largo del tiempo hemos observado que las personas se divierten con las tonterías de otras, por ejemplo, en el teatro, el cine y la televisión. Todos esos ejemplos tienen algo en común: las personas que los hacen están de acuerdo en hacerlo, ya sea porque les gusta la atención o solamente porque les divierte. Pero todo esto cambia con la llegada de los smartphones y las aplicaciones más populares para aliviar el tedio: facebook, youtube, etcétera. El combustible de estas redes sociales no es otra cosa más que las personas, y no las que lo utilizan para huir del tedio, sino personas que, fuera de su consentimiento, son usadas como objetos para satisfacer a un público que ni siquiera estaban enterados que tenían. Es en ese preciso momento, en que la masa pone su gran ojo sobre un apersona, en el que el individuo observado deja de existir como una persona que siente y sufre, sino que es "el nuevo juguete" para la diversión de la sociedad. Y debe de tener mucho cuidado el observado si osa en negarse a divertir, porque las masas no lo soltarán hasta que obtengan de él lo que 
quieren, aunque lo que tengan que violar la dignidad de la propia persona. Y al final, cuando han obtenido lo que quieren, lo tiran al piso y van en búsqueda de una nueva presa. Todo esto se da porque el tedio masivo es egoísta, nunca pensará en el que se está burlando como una persona y lo hará sufrir por esa misma razón. El ejemplo más reciente de esto es el llamado "Chavo del 8 metalero".

\section{Conclusión}

A manera de conclusión podemos decir que la voluntad, que yace en el hombre, es la causante de que esta vida sea un sufrir sin fin. La vida se nos pasa entre el sufrimiento y el tedio. La única manera que tenemos para escapar de este cruel destino es negar la voluntad misma, entregándonos al goce estético y al rechazo de los placeres, por medio del ascetismo. También podemos concluir que mientras el mundo moderno no cambie su modelo económico y social, el humano se expondrá a un deseo inagotable, al tedio y, esto, le llevará a usar a su prójimo como objeto, violentando todo imperativo categórico. 